\title{
Potencial produtivo de frutos de pepino (Cucumis sativus L.) para conserva sob diferentes sistemas de condução
}

\author{
Productive potential of cucumber fruits (Cucumis sativus L.) for preservation under different \\ driving \\ Potencial productivo de los frutos del pepino (Cucumis sativus L.) para el envasado bajo diferentes \\ sistemas de manipulación
}

Everaldo Prevital ORCID: https://orcid.org/0000-0003-1221-0526 Universidade Paranaense, Brasil E-mail: everaldo.prevital@edu.unipar.br Ana Carolina Rumão Gastaldi ORCID: https://orcid.org/0000-0002-9954-9292 Universidade Paranaense, Brasil E-mail: ana.gastaldi@edu.unipar.br Adeline dos Santos Novakoski ORCID: https://orcid.org/0000-0002-7562-3443 Universidade Estadual de Maringá, Brasil E-mail: adeline.novakoski@edu.unipar.br

João Paulo Francisco ORCID: https://orcid.org/0000-0002-7173-4461 Universidade Estadual de Maringá, Brasil E-mail: jpfrrancisco2@uem.br

Rubens Adriano da Silva ORCID: https://orcid.org/0000-0001-7511-342X Universidade Paranaense, Brasil

E-mail: rubens.silva@edu.unipar.br

Ana Daniela Lopes

ORCID: https://orcid.org/0000-0003-2027-5741 Universidade Paranaense, Brasil E-mail: anadanielalopes@prof.unipar.br

\begin{abstract}
Resumo
Com o objetivo de avaliar o potencial de produção de pepino para conserva, foi conduzido um experimento em delineamento inteiramente casualizado com três cultivares e dois manejos, adotando-se quatro repetições. As parcelas foram distribuídas em quatro linhas de plantio, via semeadura direta, com espaçamento de 1,50 $\mathrm{m} \times 0,45 \mathrm{~m}$ entre plantas. Adotou-se dois manejos: manejo 1) sem desbrota e sem poda apical; manejo 2) com desbrota e com poda apical. Após 70 dias de plantio, avaliou-se massa fresca total de frutos por planta, número médio de frutos por planta e produtividade. Entre as cultivares, destacaram-se Marinda e Amour F1 para o manejo 1, com rendimentos de massa fresca total de 1762,75 g e 1026,71 g respectivamente, e 135,69 e 79,62 número médio de frutos por planta. No manejo 2, as cultivares Marinda e Eureka obtiveram melhor rendimento, sendo a massa fresca total 1966,94 g e 1605,31 g respectivamente, e 146,17 e 90,09 número médio de frutos por planta. A cultivar Marinda tanto para o manejo 1 quanto para o manejo 2 foi a que obteve a melhor produtividade. Entre as cultivares testadas, sugere-se o cultivo das cultivares Marinda e Eureka associada à poda e capação apical.
\end{abstract}

Palavras-chave: Poda; Capação apical; Horticultura.

\section{Abstract}

In order to evaluate the potential of cucumber production for canning, an entirely randomized design experiment was conducted with three cultivars and two managements, adopting four repetitions. The plots were distributed in four planting lines, via direct sowing, with $1.50 \mathrm{~m}$ x $0.45 \mathrm{~m}$ spacing between plants. Two managements were adopted: management 1) without sprouting and apical pruning; management 2) with sprouting and apical pruning. After 70 days of planting, total fresh mass of fruits per plant, average number of fruits per plant and productivity were evaluated. Among the cultivars, Marinda and Amour F1 stood out for handling 1, with total fresh mass yields of $1762.75 \mathrm{~g}$ and $1026.71 \mathrm{~g}$ respectively, and 135.69 and 79.62 average number of fruits per plant. In handling 2 , the cultivars Marinda and Eureka obtained better yields, with a total fresh mass of 1966,94 $\mathrm{g}$ and 1605,31 g respectively, 
and 146,17 and 90,09 average number of fruits per plant. The cultivar Marinda both for handling 1 and handling 2 obtained the best yield. Among the tested cultivars, the cultivation of Marinda and Eureka cultivars associated to apical pruning and capation is suggested.

Keywords: Pruning; Apical uptake; Horticulture.

\section{Resumen}

Con el objetivo de evaluar el potencial de producción de pepinos en conserva, se realizó un experimento en un diseño completamente al azar con tres cultivares y dos manejos, adoptando cuatro repeticiones. Las parcelas se distribuyeron en cuatro líneas de siembra, mediante siembra directa, con un espaciamiento de 1,50 m x 0,45 m entre plantas. Se adoptaron dos manejos: manejo 1) sin brotar y sin poda apical; manejo 2) con trilla y poda apical. Después de 70 días de la siembra, se evaluó la masa fresca total de frutos por planta, el número promedio de frutos por planta y el rendimiento. Entre los cultivares, Marinda y Amour F1 se destacaron por el manejo 1, con rendimientos totales de masa fresca de 1762,75 g y 1026,71 g respectivamente, y 135,69 y 79,62 número medio de frutos por planta. En el manejo 2, los cultivares Marinda y Eureka tuvieron el mejor rendimiento, con una masa fresca total de $1966.94 \mathrm{~g}$ y $1605.31 \mathrm{~g}$ respectivamente, y un número medio de frutos por planta de 146.17 y 90.09. Cultivar Marinda tanto para el manejo 1 como para el manejo 2 tuvo la mejor productividad. Entre los cultivares probados, se sugiere el cultivo de los cultivares Marinda y Eureka asociados con la poda y el taponado apical.

Palabras clave: Poda; Captación apical; Horticultura.

\section{Introdução}

No Brasil, a região sul do país, com destaque para o estado de Santa Catarina, é a maior produtora de pepino, sendo responsável por cerca de $30 \%$ da produção nacional de pepino para conserva, além de possuir na região agroindústrias destinadas ao processamento do fruto (Vieira Neto et al., 2016; EPAGRI, 2019).

O pepino (Cucumis sativus) é uma planta herbácea da família das Cucurbitáceas, originária da Índia. É uma hortaliçafruto de clima quente, não suportando baixas temperaturas, principalmente nos primeiros 35 dias após a geminação (Filgueira, 2012). O consumo desta hortaliça é bem aceito por brasileiros, tanto na forma fresca, em saladas, como em conservas. Além disto, pode ser utilizado em cosméticos e medicamentos devido a suas propriedades nutracêuticas (Carvalho et al, 2013). Apresenta em sua composição cerca de $96 \%$ de umidade, sendo rico em cálcio, potássio, magnésio, fósforo e selênio. Possui poucas calorias, alto teor de fibras e vitaminas B e C, o que faz com que seja indicado em dietas devido ao baixo teor energético (Taco, 2011).

A produção de pepino vem sendo uma opção de renda para os pequenos e médios produtores, pois o ciclo da cultura é rápido podendo atingir alta produtividade, fazendo com que o produtor tenha rápido retorno financeiro em virtude dos baixos ciclos de cultivo. As cultivares disponíveis para a indústria de conserva apresentam ciclo de até 90 dias e a produção pode atingir 80 Mg ha-1, resultado esse obtido em casa de vegetação (Martins, 2004).

Para garantir uma segurança ao longo do cultivo, muitos produtores optam por implantar a cultura também no inverno, neste caso em ambientes protegidos, podendo ser empregadas técnicas hidropônicas, e sempre com a seleção de híbridos melhorados geneticamente (Vieira Neto et al., 2012; Cardoso, 2002).

Conhecer a variabilidade de hortaliças disponíveis para cultivo bem como as exigências da cultura, como a temperatura, precipitação, pH do solo, são pontos importantes para as tomadas de decisões do manejo. O cultivo de pepino para conserva requer condução e manejo adequado das plantas, para que possam expressar seu máximo potencial produtivo. Por possuir hábito de crescimento indeterminado e se desenvolver no sentido vertical ou prostrado, o tutoramento é recomendado como técnica fundamental de cultivo, onde a haste principal será conduzida por um fitilho ou estaca no sentido vertical, este somado à desbrota e poda apical (Souza, 2002; Poerschke et al., 1995).

A desbrota consiste na retirada de excesso de brotações laterais das plantas, para se ter um melhor controle do crescimento de folhas e frutos. Os brotos com 2 a $5 \mathrm{~cm}$, que surgem próximo às axilas das folhas, são retirados periodicamente (Senar, 2012). A poda apical consiste em eliminar os brotos terminal das hastes, ajudando na produção e distribuição dos fotoassimilados na planta, pela ação das auxinas, as quais são responsáveis pela perda da dominância apical. As auxinas são 
distribuídas no sentido de cima para baixo, assim a presença de auxinas nas pontas dos ramos faz com que tenha um maior crescimento nas pontas dos brotos, fazendo-se a poda da haste a quantidade de auxina se dividi nas demais gemas, fazendo com que se estimule o crescimento de ramos laterais, aumentando a produção de flores femininas e maior produtividade de frutos (Sediyama, 2014; Salata et al.,2006; Pereira et al., 2003; Melo, 2002). Além disso, promove maior aeração na parte aérea, que resulta em melhor eficiência na aplicação de produtos fitossanitários e favorecimento da entrada de luz (Martins et al., 1995).

Diante disso, o objetivo deste trabalho foi avaliar o efeito da desbrota e da poda apical sobre as características de produção de cultivares de pepino para conserva.

\section{Metodologia}

\subsection{Caracterização da área experimental}

O experimento foi conduzido entre os meses de abril e junho de 2020, na Chácara Ivaté, distrito de Herculândia, localizada a $19 \mathrm{~km}$ do município de Ivaté-PR, situada a $386 \mathrm{~m}$ de altitude com as seguintes coordenadas geográficas: Latitude $23^{\circ} 24^{\prime} 8^{\prime \prime}$ Sul e Longitude - 53²2’20”' Oeste, em solo tipo areia franca (Tabela 1).

Tabela 1. Características químicas e granulométricas do solo. Valores do $\mathrm{pH}$ do solo em $\mathrm{CaCl} 2(\mathrm{pH})$, fósforo (P), matéria orgânica (M.O), potássio (K), cálcio (Ca), magnésio, capacidade de troca catiônica (CTC) e saturação por bases (V)

\begin{tabular}{|c|c|c|c|c|c|c|c|c|c|}
\hline \multirow{2}{*}{$\begin{array}{c}\mathrm{pH} \\
\mathrm{CaCl}_{2}\end{array}$} & \multirow{2}{*}{$\begin{array}{c}\mathrm{P} \\
\mathrm{mg} \mathrm{dm}^{-3}\end{array}$} & \multirow{2}{*}{$\begin{array}{l}\text { M.O. } \\
\mathrm{g} \mathrm{dm}^{-3}\end{array}$} & $\mathrm{Ca} 2+$ & $\mathrm{K}+$ & CTC & \multirow{2}{*}{$\begin{array}{l}\mathrm{V} \\
\% \\
\end{array}$} & Areia & Silte & Argila \\
\hline & & & & $\mathrm{nol}_{\mathrm{c}} \mathrm{d}$ & $\ldots$ & & \multicolumn{3}{|c|}{.g kg $\ldots \ldots \ldots$} \\
\hline 5,52 & 90,67 & 9,85 & 3,09 & 0,48 & 6,89 & 67,06 & 840,00 & 30,00 & 130,00 \\
\hline
\end{tabular}

Fonte: Laboratório da Laborsolo do Brasil S/S Ltda (2020).

\subsection{Tratamentos e delineamento experimental}

A área experimental, foi constituída por quatro linhas de plantio espaçadas em 1,50 m e com 22,3 m de comprimento. O plantio foi realizado via semeadura direta no solo, com a utilização de duas sementes por cova. Quando as plantas se apresentavam com a $3^{\circ}$ à $4^{\circ}$ folha definitivas, foi realizado o desbaste, mantendo-se duas plantas $\mathrm{m}^{-2}$.

O delineamento experimental foi inteiramente casualizado (DIC), em esquema fatorial $3 \times 2$, com avaliação de três cultivares de pepino: Eureka, Marinda e Amour F1, combinadas com duas formas de condução: manejo 1 = sem desbrota e sem poda apical; manejo $2=$ com desbrota e com poda apical.

O experimento foi constituído por quatro repetições de cada cultivar, com parcelas experimentais compostas por 16 plantas cultivadas em faixas, com oito úteis para cada tratamento de manejo. $\mathrm{O}$ cultivo foi realizado em espaçamento de $1,50 \mathrm{~m}$ entre linhas e 0,45 m entre plantas (Figura 1). Considerou-se como parcela útil as plantas centrais das linhas internas, totalizando 32 plantas por manejo e por cultivar. Detalhes do delineamento experimental e disposição das plantas na área podem ser observados na Figura 1. 
Figura 1. Esquema de composição de experimento.

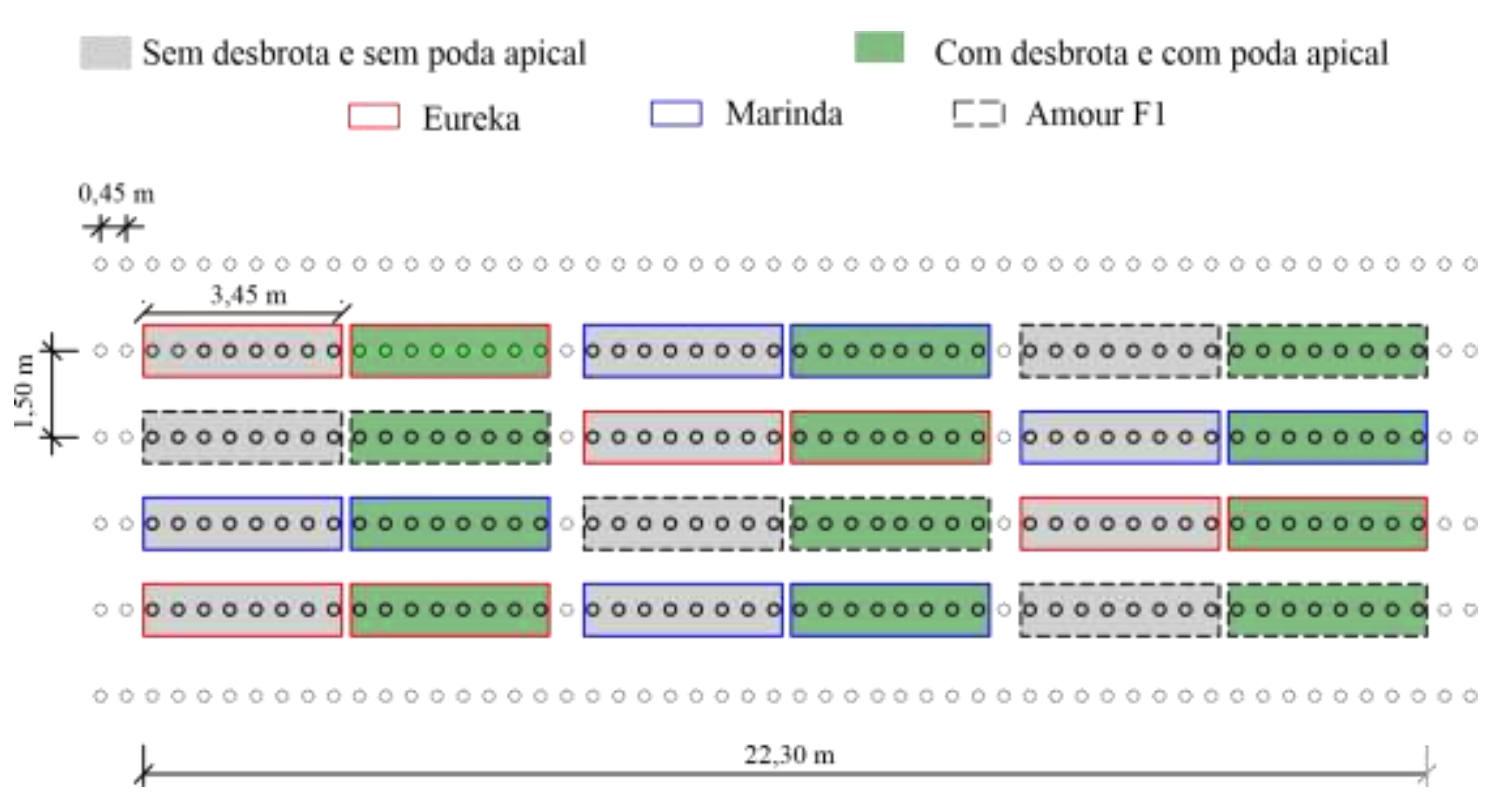

Fonte: Autores.

As plantas foram conduzidas com uma haste principal e tutoradas com fitilho plástico. Assim que iniciaram o desenvolvimento da parte aérea nos tratamentos com poda, foi realizada a remoção dos brotos laterais até o $4^{\circ}$ internódio, e a poda apical entre $18^{\circ}$ ao $22^{\circ}$ internódio, quando esses chegaram até o ponto de máximo tutoramento.

Das cultivares utilizadas para o experimento, a cultivar Eureka se caracteriza por apresentar ampla aptidão, sendo utilizada tanto para consumo in natura, quanto para a indústria, seu ciclo médio é de 50 a 55 dias. Além disso, apresenta boa uniformidade de frutos e excelente índice de produtividade, além de ter um bom desempenho em diferentes condições climáticas. Já as cultivares Marinda e Amour F1 tem a sua produção voltada mais para a indústria, também apresenta uma boa uniformidade de seus frutos. A cultivar Marinda, considerada uma planta vigorosa, apresenta frutos com casca verde escura, frutos partenocárpicos permitindo uma colheita longa e produtiva. Os frutos da cultivar Amour F1 são frutos crocantes, de coloração verde-clara, frutos cheios e pesados com espinhos, uma planta vigorosa com bom pegamento (SEMINI, 2020).

\subsection{Adubação e manejo}

A calagem e adubação foram efetuadas com base nos resultados da análise de solo e segundo a recomendação para a cultura do chuchu conforme Manual de Adubação e Calagem para o Estado do Paraná (Pauletti et al., 2017).

Após definir a área e fazer a análise de solo foi realizada a calagem com aplicação equivalente à $1,32 \mathrm{Mg} \mathrm{ha}^{-1} \mathrm{de}$ calcário calcítico (PRNT 80\%), logo após foi feito a abertura dos sulcos de plantio. A adubação foi realizada com Super Fosfato Simples $\left(166,6 \mathrm{~kg} \mathrm{ha}^{-1}\right)$ aproximadamente 30 dias antes do plantio e cama de frango como fonte de N, onde utilizou-se $88,8 \mathrm{~kg} \mathrm{ha}^{-1}$, incorporado ao solo um dia antes do plantio. As adubações complementares, em cobertura, via fertirrigação, foram realizadas a partir dos 15 dias após o plantio. A relação de produtos e dosagem estão descritas nas Tabelas 2 e 3 . O controle fitossanitário foi realizado sempre que atingido o nível de dano econômico com defensivos agrícolas registrados para a cultura. 
Tabela 2. Adubação complementar, via fertirrigação, aplicada a partir dos 15 dias após a semeadura.

\begin{tabular}{|c|c|c|c|c|c|c|c|c|c|}
\hline \multirow{3}{*}{ Produto } & \multicolumn{3}{|c|}{$1^{\text {a }}$ Semana } & \multicolumn{3}{|c|}{$2^{\mathrm{a}}$ Semana } & \multicolumn{3}{|c|}{$3^{\mathrm{a}}$ Semana } \\
\hline & \multicolumn{9}{|c|}{ (n. } \\
\hline & 1 & 2 & 3 & 1 & 2 & 3 & 1 & 2 & 3 \\
\hline C.O & 0,10 & 0,00 & 0,00 & 0,25 & 0,00 & 0,00 & 0,50 & 0,00 & 0,00 \\
\hline TM1 & 0,20 & 0,20 & 0,20 & 0,50 & 0,50 & 0,50 & 1,00 & 1,00 & 1,00 \\
\hline PM4 & 0,20 & 0,20 & 0,20 & 0,50 & 0,50 & 0,50 & 1,00 & 1,00 & 1,00 \\
\hline
\end{tabular}

Carbono orgânico $18 \%$ e $1 \%$ Ca. TM1: $1,96 \%$ N; 7,65\% $\mathrm{P}_{2} \mathrm{O}_{5} ; 7,32 \% \mathrm{~K}_{2} \mathrm{O} ; 1,44 \% \mathrm{Mg} ; 1,88 \%$ S. PM4: 5,27\% N; 5,43\% K2O; 3,97\% Ca; 0,03\% S; 0,01\% B; 0,01\% Cu; 0,01\% Mn; 0,06\% Zn; 0,05\% Ni; 0,03\% Mo e 0,05\% Fe. *C.O: Carbono orgânico; *mL por planta. Fonte: Autores.

Tabela 3. Adubação complementar, via foliar, aplicada a partir de 15 dias após a semeadura.

\begin{tabular}{|c|c|c|}
\hline \multirow{2}{*}{ Produto } & Dia 1 & Dia 2 \\
\hline & \multicolumn{2}{|c|}{ 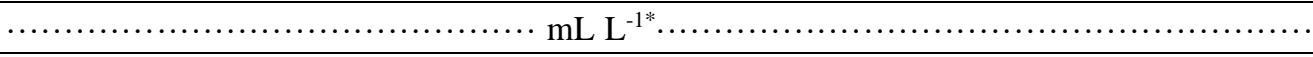 } \\
\hline Carbono orgânico & 3,0 & 5,0 \\
\hline Arenito & 2,0 & 0,0 \\
\hline Sani & 1,5 & 0,0 \\
\hline Red Copper & 0,3 & 0,0 \\
\hline Bio & 0,0 & 2,0 \\
\hline $\mathrm{CaB} \mathrm{Mg}$ & 0,0 & 3,0 \\
\hline Sweet & 0,0 & 2,0 \\
\hline
\end{tabular}

Carbono orgânico $18 \%$ e $1 \% \mathrm{Ca}$; Arenito: $1,8 \% \mathrm{Fe}$ e $7,3 \% \mathrm{Si}$; Sani: $1,1 \% \mathrm{~S} ; 1,0 \% \mathrm{Mg}$ e $1,4 \% \mathrm{Cu}$; Red Copper: $1,0 \% \mathrm{~N}$ e $30 \% \mathrm{Cu}$; Bio: $0,16 \% \mathrm{~B}$; 4,0\%S; 3,5\%Fe; 1,5\%Mg; 0,75\%Mn e 0,75\%Zn; CaBMg: 6,0\%Ca; 2,0\%Mg e 1,0\%B; Sweet: 35,0\%K2O e 45,0\% ácidos carboxílicos. *mL por litro. Fonte: Autores.

\subsection{Características avaliadas}

O experimento foi conduzido durante 70 dias e ao final foram avaliados os seguintes parâmetros: Massa fresca total de fruto por planta (MFTFP), Números médios de frutos por planta (NMFP) e produtividade total de frutos ( $\left.\mathrm{Mg} \mathrm{ha}^{-1}\right)$. A massa fresca total de frutos por planta foi obtida com o auxílio de uma balança digital, e a produtividade foi estimada com base no número de massa fresca total de frutos colhidos multiplicando pelo número de plantas por hectare (14.820 plantas). As colheitas ocorreram entre 08 de maio e 13 de junho de 2020, a cada 2 dias. O critério para colheita baseou-se nas exigências da agroindústria de pepino para conserva, que recomenda a colheita dos frutos quando estes apresentam tamanho entre 5 e 7 centímetros (Rebelo et al., 2016).

\subsection{Análise estatística}

Os parâmetros avaliados foram analisados estatisticamente por meio da análise de variância aplicando o teste $\mathrm{F}$ e desdobrando as análises sempre que a interação foi significativa.

Os dados de massa fresca total de frutos por planta (MFTFP) e número médio de frutos por planta (NMFP) não atenderam os pressupostos básicos de normalidade pelo teste de Shapiro-Wilk. Dessa forma, adotou-se o teste de Box-Cox para encontrar a transformação mais adequada, com o objetivo de alcançar um comportamento aproximadamente normal. A análise de Box-Cox gerou um valor de $\lambda=0,2$ assim, todos os dados foram corrigidos com a utilização das variáveis como base e o valor de $\lambda$ como expoente. Após transformação dos dados, os mesmos foram submetidos à análise de variância, e aplicado o teste de Tukey a 5\% de probabilidade. As análises estatísticas foram realizadas por meio do programa estatístico R, versão 2.2.1 (R. Development Core Team, 2013).

\section{Resultados}

De acordo com as análises estatísticas, constatou-se que as características massa fresca total de frutos por planta 
(MFTFP) e número médio de frutos por planta (NMFP) apresentaram efeitos significativos entre os tratamentos. A interação entre os fatores cultivares e tipos de manejo indicou, para a variável MFTFP, que as cultivares Amour F1, Eureka e Marinda diferiram estatisticamente entre si $(\mathrm{p} \leq 0,05)$ tanto no Manejo 1 (sem desbrota e sem poda apical) quanto no Manejo 2 (com desbrota e com poda apical).

No desdobramento das cultivares, dentro dos tipos de manejo, verificou-se que cada cultivar diferem para cada um dos manejos adotados. A cultivar Marinda obteve maior massa fresca total de frutos por planta, no manejo 1 $\left(1768,40 \mathrm{~g} \mathrm{planta}^{-1}\right)$ com uma massa de fruto por planta de $13,11 \mathrm{~g} \cdot$ fruto, o equivalente a 26,20 Mg $\cdot \mathrm{ha}^{-1}$. No manejo 2 a massa fresca total de frutos por planta foi de 1966,94 g. planta ${ }^{-1}$, o equivalente a $29,15 \mathrm{Mg} \mathrm{ha}^{-1}$ e uma massa de frutos por planta de 13,45 g.frutos, uma porcentagem de 11,22\% a mais que o manejo 1, resultado parecido com o de Resende (1999), que obteve $29,72 \mathrm{Mg} \mathrm{ha}^{-1}$ com a cultivar Indaial.

A cultivar Amour F1 obteve a segunda melhor MFTF, no manejo 1 (1026,88 planta-1), totalizando $15,22 \mathrm{Mg} \mathrm{ha}^{-1} \mathrm{e}$ uma média de massa de fruto de 12,78 g.fruto, no entanto, com baixa MFTF no manejo 2 (948,34 g. planta $\left.{ }^{-1}\right)$, alcançando $14,05 \mathrm{Mg} \mathrm{ha}^{-1} \mathrm{e}$ uma massa de fruto por planta de 11,78 $\mathrm{g}$.fruto, isso ocorreu, pois, a massa de fruto foi menor no manejo com desbrota e poda apical. A cultivar Eureka foi inferior às demais cultivares no manejo 1, com 735,78 g.planta-1 (10,9 Mg ha-1) e uma massa de frutos de 17,93 g.fruto, porém no manejo 2 esta cultivar obteve uma MFTF de 1605,31 g. planta $^{-1}$ $\left(23,79 \mathrm{Mg} \cdot \mathrm{ha}^{-1}\right)$, um aumento de 118,17\%, superando a cultivar Amour F1 (Tabela 4).

Tabela 4. Massa fresca total de frutos (g) por planta de pepino submetida à diferentes manejos de condução.

\begin{tabular}{lccc}
\hline Cultivares & Manejo 1 & Manejo 2 & CV (\%) \\
\hline Amour F1 & $1026,88 \mathrm{aB}$ & $948,34 \mathrm{bC}$ & \\
Eureka & $735,78 \mathrm{bC}$ & $1605,31 \mathrm{aB}$ & 3,50 \\
Marinda & $1768,40 \mathrm{bA}$ & $1966,94 \mathrm{aA}$ & \\
\hline
\end{tabular}

*Médias seguidas pela mesma letra minúscula na linha e maiúscula, na coluna, não diferem entre si pelo teste Tukey a 5\% de probabilidade. CV: Coeficiente de variação. Fonte: Autores.

Para a variável número total de frutos por planta (NMFP) as cultivares também diferiram entre si $(p \leq 0,05)$ tanto para o manejo 1 quanto para o manejo 2 (Tabela 5). A cultivar que apresentou maior NMFP foi Marinda, em ambos manejos, contudo, para as três cultivares avaliadas o maior NMFP foi verificado no manejo 2.

No desdobramento de cada cultivar nos tipos de manejo, apenas Amour F1 não apresentou diferença no número de frutos produzidos quando manejada com ou sem desbrota e poda apical. As demais cultivares, por sua vez, diferiram quanto à produção de frutos nos Manejos 1 e 2. O NMFP foi superior para a cultivar Marinda tanto no manejo 1 quanto no manejo 2 (134,41 e 146,15 respectivamente) diferindo 8,41\% entre os manejos no número de frutos por planta. A cultivar Amour F1 obteve a segunda melhor produção de frutos no manejo $1(80,35)$, no entanto, com produção de frutos inferior às demais cultivares no manejo 2 (80,53), sendo sua produção de frutos apenas $0,23 \%$ maior que o manejo 1 , não diferindo estatisticamente. A cultivar Eureka foi inferior às demais para NMFP, no manejo 1 (41,03), tendo melhora na produção no manejo 2 (86,84), obtendo uma produção 111,65\% maior no manejo 2, diferindo do manejo 1 (Tabela 5). 
Tabela 5. Número total de frutos por planta de pepino conduzido em diferentes sistemas de manejo.

\begin{tabular}{lccc}
\hline Cultivares & Manejo 1 & Manejo 2 & CV $(\%)$ \\
\hline Amour F1 & $80,34 \mathrm{aB}$ & $80,53 \mathrm{aC}$ & \\
Eureka & $41,03 \mathrm{bC}$ & $86,84 \mathrm{aB}$ & 7,38 \\
Marinda & $134,81 \mathrm{bA}$ & $146,15 \mathrm{aA}$ & \\
\hline
\end{tabular}

*Médias seguidas pela mesma letra minúscula na linha e maiúscula, na coluna, não diferem entre si pelo teste Tukey a 5\% de probabilidade. CV: Coeficiente de variação. Fonte: Autores.

\section{Discussão}

Martins et al. (1995), ao testarem dois tipos de poda (drástica e arejamento) alcançaram produção de $20 \mathrm{~kg} \cdot \mathrm{m}-2 \mathrm{com}$ a poda de arejamento em casa de vegetação, evidenciando que a poda de arejamento contribui para a produção de pepino, mostrando os melhores resultados e sendo recomendada para plantas tutoradas.

Sediyama et al. (2014), entretanto, verificaram efeito negativo da desbrota e capação apical sobre a produtividade de pepino, uma vez que plantas submetidas à desbrota e capação obtiveram 49,77 $\mathrm{Mg} \mathrm{ha}^{-1}$ e aquelas sem aplicação de nenhum manejo de condução apresentaram produtividade de 53,56 $\mathrm{Mg} \mathrm{ha}^{-1}$. Segundo os autores, podas mais profundas, ou seja, quando se fez poda, capação e podas de hastes laterais, podem reduzir em torno de $20 \%$ a produtividade, comparada a testemunha.

Trabalhos realizados por Pereira et al. (2003), com melão, também da família das cucurbitáceas, mostrou que as plantas podadas obtiveram maior número de frutos e massa média em relação às não podadas e que, com o aumento na densidade de plantas houve o inverso, ou seja, menor número de frutos e massa média dos mesmos, também constataram que o maior número de frutos de plantas podadas em relação às não podadas pode ser atribuído ao maior número de ramificações estimuladas pela poda apical e consequentemente obteve um maior número de gemas floríferas.

Namura e Cardoso (2000) trabalhando com o pepino japonês, híbrido Hokuro enxertado sobre abóbora, verificaram redução na produção e qualidade de frutos, proporcional ao nível de desfolha, mas que pode vir a ajudar nos tratos culturais das plantas e ajudar nas colheitas, as plantas testemunha (crescimento livre), apresentou um maior número de frutos totais (31,96), porém menor número de frutos comerciais $(18,45)$, já o tratamento em que foi realizado a eliminação dos brotos laterais, ramas laterais, frutos defeituosos jovens, poda da haste foi o que obteve um maior número de frutos comerciais (20,53) e maior porcentagem de nós com ramos laterais $(65,20 \%)$, os tratamentos com $50 \%$ e $75 \%$ de desfolhas, prejudicou a produção e qualidade dos frutos.

As diferenças entre os resultados apresentados pelos autores podem ser em função das diferentes regiões, cultivares e até mesmo os cuidados com a condução da cultura. Outra questão é a padronização dos frutos colhidos, pois influencia na massa de frutos.

Entretanto a desbrota e a poda apical ainda é questionável no meio cientifico, pois apresenta para algumas variedades uma resposta positiva, porém, para alguns autores como descrito por Martins et al. (1995), a poda não apresenta diferença nos resultados, na qualidade dos frutos e produtividade, além de trazer um maior gasto e trabalho na condução da cultura, já que esta demanda uma maior mão de obra.

\section{Considerações Finais}

Dentre as cultivares testadas sugere-se o cultivo das cvs. Marinda e Eureka associado à poda e capação apical para maior produção de massa fresca de frutos por planta, número médio de frutos por planta e maior produtividade. Contudo, para as condições de condução adotadas neste trabalho, não se recomenda a realização da desbrota e a poda apical para a cultivar Amour F1. 
Research, Society and Development, v. 11, n. 1, e8011124841, 2022

(CC BY 4.0) | ISSN 2525-3409 | DOI: http://dx.doi.org/10.33448/rsd-v11i1.24841

\section{Referências}

Cardoso, A. I. I. (2002). Avaliação de cultivares de pepino tipo caipira sob ambiente protegido em duas épocas de semeadura. Bragantia, 61(1), 43-48.

Carvalho, A. D. F., Amaro, G. B., Lopes, J. F., Vilela, N. J.,Filho, M. M., \& Andrade, R. (2013). A cultura do pepino. Embrapa Hortaliças.

EPAGRI. (2019). Epagri apresenta tecnologias no Fórum Brasileiro de Produção de Pepino. Epagri.

Filgueira, F. A. R. (2012) Novo Manual de Olericultura: agrotecnologia moderna na produção e comercialização de hortaliças. UFV.

Kist, B. B. (2019). Anuário brasileiro de Horti\&Fruti 2019. http://www.editoragazeta.com.br/sitewp/wp-content/uploads/2019/07/HortiFruti

Kretchman, D. W. (1988). Práticas culturais para maximizar rendimento e qualidade de vegetais para processamento. Acta Horticulture.

Lamas, F. M. (2020). Artigo: Tecnologia na agricultura. https://www.embrapa.br/busca-de-noticias/-/noticia/30015917/artigo-a-tecnologia-na-agricultura.

Martins, C. N. (2004). Pepino: produção triplicada. Revista Cultivar Hortaliças e Frutas.

Martins, S. R., Fernandes, H. S., Postingher, D., Schwengber, J. E., \& Quintanilla, L. F. (1995). Avaliação da cultura do pepino (Cucumis sativus L.), cultivado em estufa plástica, sob diferentes tipos de poda e arranjos de plantas. Revista Brasileira de Agrociência, 1(1), 30-33.

Nomura, E. S. \& Cardoso, A. I. I. (2000). Redução da área foliar e o rendimento do pepino japonês. Scientia Agricola, 7(2), 257-261.

Pauletti, V. \& Motta, A. C. V. (2017). Manual de Adubação e Calagem para o Estado do Paraná. SBCS-Sociedade Brasileira de Ciência do Solo.

Pereira, F. H. F., Nogueira, I. C. C., Pedrosa, J. F., Negreiros, M. Z., \& Bezerra Neto, F. (2003). Poda da haste principal e densidade de cultivo sobre a produção e qualidade de frutos em híbridos de melão. Horticultura Brasileira, 21(2), 191-196.

Poerschke, P. R. C., Buriol, G. A., Streck, N. A., \& Estefanel,V. (1995). Efeito de sistemas de poda sobre o rendimento do tomateiro cultivado em estufa de polietileno. Ciência Rural, 25(3), 379-384.

R Development Core Team. (2013). A language and environment for statistical computing and graphics. R Foundation for Statistical Computing

Rebelo, J. A., Schallenberger, E., Cantú, R. R., \& Morales, R. G. F. (2016). Produtividade de pepino em função de diferentes sistemas de cultivo. Revista:Ambiência, 12(4), 825-833.

Resende, G. M. (1999). Produção de pepino para conservação na região Norte de Minas Gerais. Horticultura Brasileira, 17(1), 57-60.

Salata, A. C., Bertolini, E. V., \& Cardoso, A. I. I. (2006). Produção de pepino com poda da haste principal. UNESP-FCA.

Sediyama, M. A. N., Nascimento, J. L. M., Lopes, I. P. C., Lima, P. C., Vidigal, S. M., \& Almeida, C. H. S. (2020). Manejo da poda em plantas de pepino tipos Aodai, Japonês e Caipira. Horticultura Brasileira, 32(4), 4041-4049.

Senar. (2012). Hortaliças, cultivo de hortaliças frutos. Serviço Nacional de Aprendizagem Rural. SENAR.

Shinohara, S. (1984). Vegetable seed. production of japan. SAACEO.

Souza, I. Cultura de Pepino para Conserva. EMATER.

Taco. (2011). Tabela brasileira de composição de alimentos-TACO. UNICAMP.

Vieira Neto, J., Menezes Júnior, F. O. G., \& Gonçalves, P. A. S. (2012). Produtividade de cultivares de pepino para conserva em manejo convencional e alternativo. Horticultura Brasileira, 15(3), 93-101.

Vieira Neto, J., Menezes Júnior, F. O. G., \& Gonçalves, P. A. S. (2016). Produtividade de cultivares de pepino para conserva em manejo convencional e alternativo. Revista Brasileira de Agroecologia, 11(3), 272-277. 